Of the 14 patients investigated before treatment, three (Cases 2, 3, and 4) had hyperuricaemia. (It may be added that a further six hypertensive patients not requiring hypotensive agents were investigated, of whom one female had hyperuricaemia.)

The length of time the subject had been receiving guanethidine did not influence the uric acid levels.

\section{Discussion and CONClusions}

The results show that guanethidine does not cause hyperuricaemia as Dollery et al. (1960) suggested for chlorothiazide, pempidine, and mecamylamine. Two of three patients in our series did in fact have hyperuricaemia while receiving chlorothiazide, which is in keeping with this action of chlorothiazide reported by Oren et al. (1958), Laragh (1958), Dinon et al. (1958), Aronoff (1960), and Warshaw (1960).

Of the three patients (two females and one male) found to have hyperuricaemia on guanethidine alone, two were known to have raised uric acid levels before treatment ; the third subject unfortunately did not have his uric acid estimated before treatment. This finding is similar to those of Dollery et al. for hypertensive subjects having hyperuricaemia without drug treatment $(7.3 \%$ malcs, $18.5 \%$ females). It is not known whether this is due to primary hyperuricaemia or to early renal failure secondary to the hypertension. As Dollery et al. noted, there is no obvious relationship between serum uric acid and serum urea concentrations. However, we hope to carry out clearance tests on hypertensive patients with and without drug therapy which may elucidate this point.

These results support the hypothesis that hyperuricaemia due to treatment of hypertension with chlorthiazide and ganglion-blocking agents is drug-induced and not related to alteration of glomerular filtration caused by a fall in blood-pressure. In our series 15 of the 22 patients achieved a satisfactory mean fall in blood-pressure without a significant rise in the serum uric acid. Although the control of hypertension is easier using thiazide diuretics with guanethidine (Hilden, 1960 ; Jaquerod and Spuehler, 1960 ; Blanchard and Essigman, 1961), the possible danger of prolonged hyperuricaemia causing further renal damage in hypertensives, as is found in patients with primary hyperuricaemia, has to be considered. It may be better to continue with guanethidine alone, and reserve the thiazide diuretics for patients proving resistant to guanethidine, for the latter at present appears to be free from the danger of causing hyperuricaemia. A prolonged study, comparing guanethidine alone and in combination with the thiazide diuretics, is required.

We thank Dr. R. S. Bruce Pearson and Dr. P. Hugh-Jones for permission to study patients under their care, and Professor C. H. Gray for placing laboratory facilities at our disposal.

LIONEL FRY, M.B., B.Sc., M.R.C.P., Medical Registrar.

KeITH A. Barlow, M.B., B.S., King's College Hospital. Demonstrator in Pathology.

\section{REFERENCES}

Aronoff, A. (1960). New Engl. J. Med., 262, 767.

Blanchard, G., and Essigman, W. (1961). Lancet, 2, 334

Dinon, L. R., Kim, Y. S., and Vander Veer, J. B. (1958). Amer. J. med. Sci., 236, 533.
Dollery, C. T., Duncan, H., and Schumer, B. (1960). Brit. med. J., 2,832 .

Hawk, P. B., Oser, B. L., and Summerson, W. H. (1954). Practical Physiological Chemistry; 13th ed., p. 559. Blakiston, New York.

Hilden, T. (1960). Essential Hypertension, edited by K. D. Bock and P. T. Cottier, p. 261. Springer, Berlin.

Jaquerod, R., and Spuehler, O. (1960). Schweiz. med. Wschr., 90. 113.

Laragh, J. H. (1958). Ann. N.Y. Acad. Sci., 71, 409.

Marsh, W. H., Fingerhut, B., and Kirsch, E. (1957). Amer. J. clin. Path., 28, 681.

Oren, B. G., Rich, M., and Belle, M. S. (1958). J. Amer. med. Ass., 168, 2128.

Skeggs, L. T. (1957). Amer. J. clin. Path., 28, 311.

Warshaw, L. J. (1960). J. Amer. med. Ass., 172, 802.

\section{Medical Memoranda}

\section{Peutz-Jeghers Syndrome in Childhood : Unusual Radiological Features}

Familial intestinal polyposis, associated with a characteristic circumoral spotty pigmentation, was first recognized by Peutz (1921) in Holland. Jeghers et al. (1949) described a further 10 cases, and Dormandy (1957) made an extensive review of the literature, after describing 21 cases of the condition in five families. Recurrent intussusception is a common occurrence in the disease, and the following case history is of interest because of the unusual radiological demonstration of such an intussusception before operation.

\section{CASE History}

An 8-year-old boy was admitted to hospital on November 2, 1959, with abdominal pain, vomiting, and diarrhoea. For two years he had suffered from acute attacks of central abdominal pain and vomiting. He was eating poorly, had lost weight, and also complained of frequent headaches. He had had surgical treatment for a chronic antral sinusitis.

Family History.-He had two sisters, and one, aged 10 years, had circumoral pigmentation but was otherwise well. His mother, aged 34, said she had brown spots around her mouth until puberty, and had had a thyroidectomy for thyrotoxicosis. A maternal aunt was well but had complained of abdominal colic in the past. The maternal grandfather of the patient had died from " cancer of the bowel." The boy's father was healthy, but three of his sisters suffered from pulmonary tuberculosis.

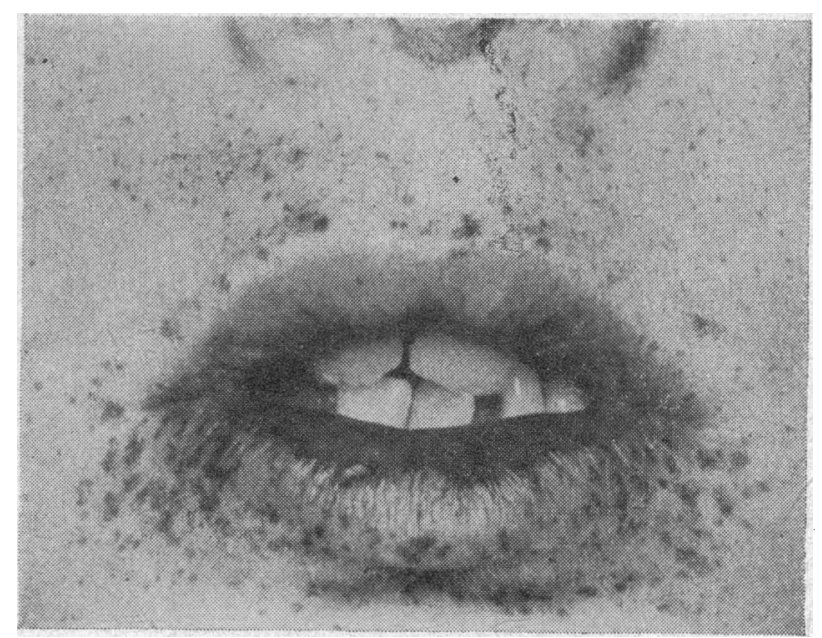

FIG. 1.-Linear streaks and brown spots of circumoral pigmentation on lips and skin. 
Examination.-On admission he was pale, emaciated, and very dehydrated, weighing $47 \mathrm{lb}$. $(21.3 \mathrm{~kg}$.$) , with a$ temperature of $99.4^{\circ} \mathrm{F}$. $\left(37.4^{\circ} \mathrm{C}\right.$.). Blood-pressure was 70/50. Around the mouth there were irregular brown

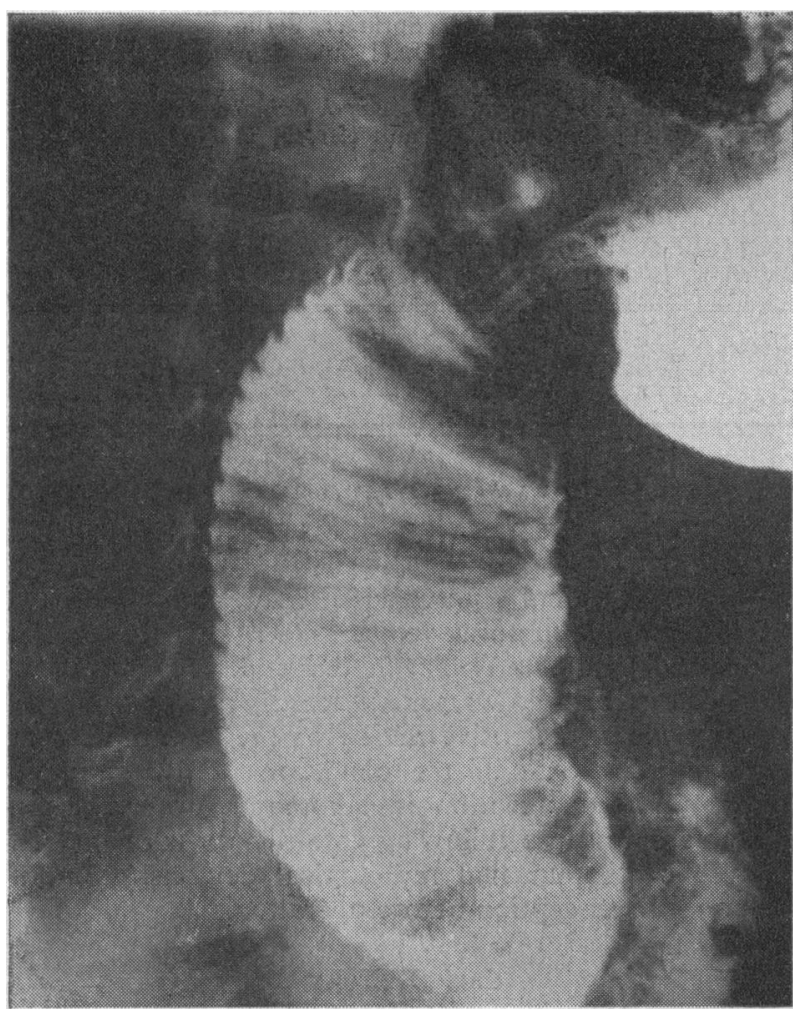

FIG. 2.-Barium-meal radiograph showing dilatation of duodenum, string-like shadow of intussusceptum, and ring shadows surrounding intussuscipiens.

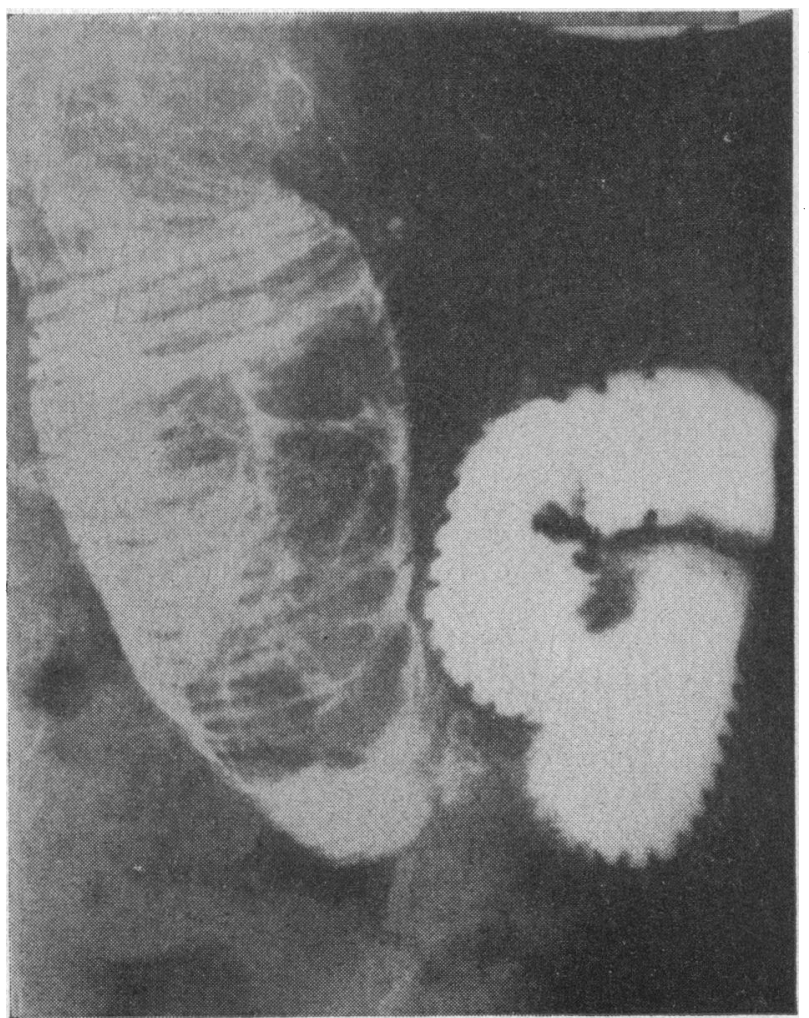

FIG. 3.-Radiograph showing several rounded filling defects within the intussusception. patches and linear streaks of pigmentation, most apparent on the lower lip and extending on to the buccal mucosa (Fig. 1). A few scattered spots of pigmentation were present on the cheeks and backs of the hands. The abdomen was scaphoid, and well-marked "ladder pattern" peristalsis could be seen. There was some epigastric fullness and tenderness, but no abnormal masses were felt in the abdomen. He appeared to have some neck stiffness and a positive Kernig sign. The remainder of the physical examination was negative, apart from mucopus in the nose.

Diagnosis.-In view of the family history of tuberculosis, a possible diagnosis of tuberculous meningitis was considered, but the cerebrospinal fluid was normal (protein $20 \mathrm{mg} . / 100 \mathrm{ml}$., sugar $90 \mathrm{mg} . / 100 \mathrm{ml}$., cells $3 / \mathrm{c} . \mathrm{mm}$.). The haemoglobin was $11.5 \mathrm{~g} . / 100 \mathrm{ml}$. Urine showed a trace of acetone only. Biochemical investigations confirmed a suspected metabolic alkalosis; alkali reserve $38 \mathrm{mEq} / \mathrm{l}$, potassium $2.4 \mathrm{mEq} / \mathrm{l}$., sodium $146 \mathrm{mEq} / 1$., total protein $7.3 \mathrm{~g} . / 100 \mathrm{ml}$. The presence of the circumoral pigmentation pointed to a diagnosis of multiple intestinal polyposis, associated with an intussusception. His dehydration was corrected by intravenous fluids and gastric suction. On November 9 a barium-meal examination showed that the second part of the duodenum was e nor mous 1 y dilated. Thin lines of barium could be seen running at right angles to the denser ring-like shadows at the upper end of this loop. The appearances were those of an intussusception, the stringlike shadows depicting the intussusceptum and the ring shadows the surrounding intuss u s c i p i e n s. Rounded filling defects suggested the presence of polypi (Figs. 2 and 3).

Operation.--On November 11 a laparotomy was

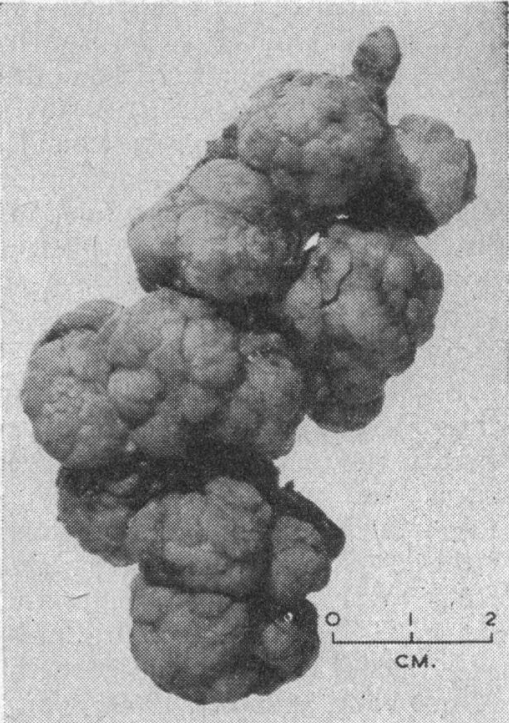

Fig. 4-Mass of pedunculated polyps removed from prepyloric gastric mucosa at operation. performed under general anaesthesia by $\mathrm{Mr}$. Duncan Forrest. The duodenum and the upper half of the jejunum were found to be enormously distended and their walls hypertrophied. There was an intussusception beginning at the prepyloric region of the stomach and extending to the upper jejunum. The apex of this intussusception was a large mass of pedunculated polyps which arose from the prepyloric gastric mucosa. These had led to increased peristalsis and eventual hypertrophy of the duodenal and jejunal musculature. There were also two similar but easily reducible intussusceptions in the more distal jejunum. The large intussusception could not be completely reduced, and it was necessary to excise the prepyloric region of the stomach with its pedunculated mass of polyps (Fig. 4), the pylorus, and an inch of the first part of the duodenum. End-to-end anastomosis was then performed. No further polyps could be felt in the jejunum or could be seen with a sigmoidoscope in several feet of the upper intestine. The mesenteric glands draining the affected duodenum and jejunum were greatly enlarged.

Histology.-Histological sections of the polyps were examined by Dr. Ian Dawson, who reported on them as follows. "The polyp can be seen to be arising from the 
superficial epithelium. It consists of regular gland elements which are larger than normal but not hyperplastic, separated by a stroma which is vascular and in places oedematous but does not differ essentially from the normal lamina propria. The individual epithelial cells are tall columnar cells with basal nuclei and do not differ essentially from normal epithelial cells. These polyps are essentially hamartomas or malformations and not benign neoplastic polyps like the single or multiple sessile or pedunculated adenomas of large intestine."

Biopsy of one of the pigmented spots showed melanin pigment in the basal cell layer of the buccal mucosa. Sigmoidoscopy and cystoscopy before discharge, a month after his operation, did not reveal any polyps in the large bowel or bladder. There was no evidence of nasal polyps. Apart from some short attacks of abdominal colic and constipation, he has remained well since his last admission.

\section{COMMENT}

Few cases of the Peutz-Jeghers syndrome have been reported in childhood. There were four children from three families in Dormandy's series. Fisher (1951) reported one of the youngest, in a boy aged 7 years, with multiple polyposis of the stomach, duodenum, and jejunum. The radiological findings in the patient were unusual and remarkable in that such appearancesdemonstration of an intussusception and polyposis-are rarely seen or recorded in the Peutz-Jeghers syndrome. Behrer (1951) recorded the history of a 14-year-old boy with the Peutz-Jeghers syndrome who was initially thought to have a bleeding peptic ulcer and in whom barium-meal examination showed a jejunal intussusception. The radiological appearances were strikingly similar to the films taken in our case. Colquhoun (1959) demonstrated a jejunal intussusception by barium-meal in a 33-year-old woman who was later found to have an isolated jejunal polyp as a cause of her intussusception. Buckstein (1953) mentioned the case of a 6-year-old child with melaena and anaemia, in whom a barium study showed a dilated segment of small bowel, with an irregular longitudinal line running through it, caused by an intussusception, led by an adenomatous polyp. Although intestinal polyps may appear as filling defects on ordinary barium studies, their detection demands a high degree of suspicion on the part of the radiologist. Special methods such as the double-contrast technique, whereby air is injected after a barium enema, are particularly valuable in visualizing these lesions (Buckstein, 1953 ; Dormandy, 1957).

I am indebted to Dr. H. M. T. Coles, under whose care the patient was admitted, and to Dr. Basil Strickland, Mr. Duncan Forrest, and Dr. Ian Dawson for their advice on the radiological, surgical, and pathological findings. Dr. Peter Hansell kindly took the photographs.

\section{J. D. ShewaRd, M.D., M.R.C.P.,} Senior Registrar.

Westminster Children's Hospital, London.

\section{REFERENCES}

Behrer, M. R. (1951). J. Pediat., 38, 641

Buckstein, J. (1953). The Digestive Tract in Roentgenology, 2nd ed., vol. 2, p. 682. Lippincott, Philadelphia.

Colquhoun, J. (1959). Brit. J. Radiol., 32, 329.

Dormandy, T. L. (1957). New Engl. J. Med., 256, 1093, 1141, 1186.

Fisher, O. D. (1951). Gt Ormond St. J., No. 2, p. 151.

Jeghers, H., McKusick, V. A., and Katz, K. H. (1949). New Engl. J. Med.. 241, 993, 1031.

Peutz, J. L. A. (1921). Ned. Maandschr. Geneesk., 10, 134.

\section{Peutz-Jeghers Syndrome : A Further - Family History}

The association of small-intestinal polyposis and buccal pigmentation, often presenting as a familial condition, has aroused great interest in recent years. In 1896 Jonathan Hutchinson described twin girls who had a peculiar spotty pigmentation around their mouths. In 1919 Parkes Weber recorded that one of the twins had died 11 years later after an operation for intussusception. Peutz (1921) noted the familial association and Jeghers et al. (1949) reviewed the literature and described 10 further cases. This condition is consequently referred to as the Peutz-Jeghers syndrome. Tanner (1951) described the first case in this country, and the recent world literature from time to time records further cases. We present another family in which mother and daughter were affected by the disease.

CASE 1

A girl aged 9 was admitted to Southampton Children's Hospital on June 3,1961, as an acute abdominal emergency. She complained of severe abdominal pain of 36 hours' duration, associated with vomiting. The pain was central and subumbilical, constant in nature, but with occasional colicky spasms. The patient had vomited eight times on the previous day and six times on the day of admission. She gave a history of a number of similar but milder attacks over the previous six months and was said to go pale during these episodes. These were associated with very marked borborygmi, which her mother said could be heard across the room. On account of these attacks she had been referred to a paediatrician who concluded that they were hysterical in nature and attributed them to her change of schoolwhich she did not like. There was no other relevant history.

On examination her temperature was $98^{\circ} \mathrm{F}$. $\left(36.7^{\circ} \mathrm{C}\right.$.), pulse 120 , respirations 24 . The most arresting feature was the considerable freckling of the face and circumoral

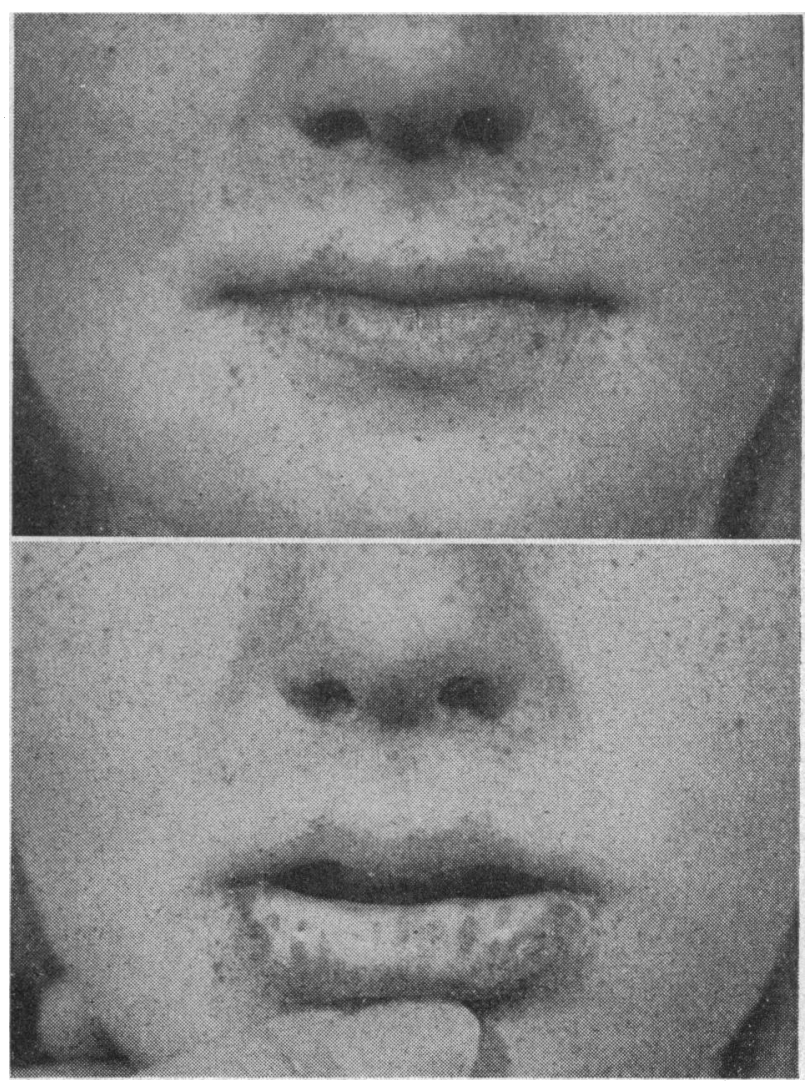

Fig 1.-Photographs of Case 1. 